Research Article

\title{
Signatures of Transient Overvoltages in Low Voltage Power Systems in Tea Factories and Their Implications on Insulation Deterioration and Allied Power Quality Issues
}

\author{
Earl A. R. L. Pannila ${ }^{1}{ }^{1}$ and Mahesh Edirisinghe $\mathbb{i D}^{2}$ \\ ${ }^{1}$ Faculty of Engineering and Technology, Sri Lanka Technological Campus, Padukka 10500, Sri Lanka \\ ${ }^{2}$ Department of Physics, University of Colombo, Colombo 00300, Sri Lanka \\ Correspondence should be addressed to Earl A. R. L. Pannila; chanakyap@sltc.ac.lk
}

Received 30 September 2021; Accepted 30 October 2021; Published 19 November 2021

Academic Editor: Renato Procopio

Copyright (c) 2021 Earl A. R. L. Pannila and Mahesh Edirisinghe. This is an open access article distributed under the Creative Commons Attribution License, which permits unrestricted use, distribution, and reproduction in any medium, provided the original work is properly cited.

\begin{abstract}
Electrical equipment and supply cables demand a better quality of supply, with the recent advancements in integrated sensitive solid-state controls. Divergently, proliferated heavy inductive motors and some performance additions based on power electronics have introduced power quality issues to the network. Thus, this study mainly investigates the impact of switching transients generated by electromechanical machines in industrial power systems on insulation deterioration while taking transient overvoltages due to capacitor bank switching also to support. Transients with a high rate of rise are likely to catalyze the degradation of the insulation quality and break down the insulating material through ionization. These steeply passing overvoltage stresses let partial discharges ensue, which can attack the insulation over long service. To unveil this danger, 314 common-mode transient waveforms were measured in the electrical machines of five tea factories in Sri Lanka, in a 50 ms measurement window, taken in 55 measuring attempts. Most of the transients observed are in the form of a damped oscillatory waveform tailed by fast exponential collapse. That correlates to insulation degradation having a very steep rise as $30.04 \mathrm{~V} / \mathrm{ns}$, the highest at the withering section. When machines are heavily loaded, situations tend to generate transients with high amplitudes. There were transient bursts that spread as $426.3 \mathrm{~ms}$, while $14 \mathrm{~ns}$ fast rise times were recorded from withering motors. Unlike electrical resonance and power-frequency overvoltages, electromagnetic switching transients last even less than $100 \mathrm{~ms}$. To underline this, an analysis of the frequency domain of transients was also presented, which proves high density of high-frequency components reaching $10^{7} \mathrm{kHz}$ range. Accepting the fact that frequency and amplitude are always under the influences of innumerable dynamics, the observational evidence of the study endorses that electrical stress built by the transient nature of the factories reduces the life expectancy of electrical insulation.
\end{abstract}

\section{Introduction}

In the modern industrial environment, power quality has become a sensitive burden to deal with. This is due to the impact it builds with a growing number of complaints that $\log$ to electrical manufacturers, electricity providers, and end-users. The different roots of power quality issues are majorly reported from severe to modest change voltage disturbances and power supply variations [1]. Supplying steady, trustworthy, and high-grade power to clients is always matching the supply upon demand. Therefore, handling the load with demand management initiatives and improving the power quality have ultimately become the current trend [2].

The major component of voltage disturbance is accounted by a transient overvoltage due to various causes in machinery in industrial facilities. An abrupt change in current demand or load change can initiate a transient at any instance in a system primarily. Although the time that an electrical transient lasts in the system is trivial at a glance, the system gets exposed to high voltage and current upsurges. This might cause severe harm to the equipment and make 
the subsequent repair costly in both time and money. Switching of capacitor banks parades a notorious role in industrial facilities, since the majority of such environments are demanding the requirement of capacitor bank installations to keep the power factor of the facility at a stipulated level [3]. The insulation of the different sections of the system must be classified to keep the least disturbed, and electrical distortions only happen at intentional points. The requirement to cut the amount of insulation in the network through effective insulation coordination becomes more critical with increasing supply voltage. The definitive intention is to reduce the damage, system outages, and equipment upsets caused by insulation failure to a financially and operationally tolerable level. Therefore, this paper reports the transient influence on insulation quality in an industrial installation while taking the diffusion of capacitor bank switching transients also into the matter. It is done based on the observations carried out at several large-tomedium-scale tea factories in Sri Lanka. This further discusses how the situation will affect the capacitor bank failures in industrial facilities due to supply system irregularities.

The alternating sine wave may diverge from its ordinary form whenever there is a sudden change in the circuit condition, such as by faults, connection or disconnection of heavy loads, or breakdowns. These rapid rise anomalies from the normal state may lead to a burst of energy in power systems. This energy-derived voltage stress can explode as transient overvoltage which can cause damage to the supply lines and relevant machines. The rapid collapse of its magnetic field induces a transient voltage which becomes superimposed onto the steady-state supply. They have the potential to cause a boundless impact on system reliability, most critically their insulation, where they can come internally or externally $[4,5]$. As the study plans to discuss more on the transient impact on insulation failure on power equipment and installation, the analysis will aim down to forecast the insulation failure against transients extracted.

The degree of insulation degradation in electrical machinery can be heavily affected by many functional aspects like the voltage, frequency, temperature, and pressure independently or adjunctively [6-8]. When transients are present, instantaneous voltage magnification happens across the inductive element due to its inductive reactance $\omega L$. As this is frequency-dependent, reactance will rise as the frequency increases. In higher horsepower rated rotating machines, turn to the ground and interturn failures in insulation are triggered by supplementary dielectric stresses that occur during commutations [6, 9-11]. As discussed in many observations, steep fronted switching transients are the principal reason for the dielectric stress of winding insulation as they produce irregular voltage distributions in the electrical machines $[9,11]$.

Owing to the draw of high current, interturn insulation of motor failure ends up in undue heating. This makes the insulation of the ground wall fail. Insulation failure of turns is visible in the stator coils as melted conductors and maybe a cavity in the main insulation to earth fault [12]. Switching transients, by nature, have a slow rise, typically above $10 \mathrm{~ms}$. Even though the time they last is small, they carry a considerable amount of energy as reported in [13], which might degrade or completely damage the insulating characteristics of the installation or terminal utility. Research reveals that small rated low and medium voltage motors are more likely at risk due to steeply rising voltage transients compared to larger motors [12].

The scientific literature addressing localized degradation of insulators reveals that damages could happen due to some factors: thermal, mechanical, and electrical stresses alone or synergized. These factors have been proven to be driving the insulation in electrical machines to a catastrophic breakdown by deteriorating its characteristics [4, 7, 14-16]. Providing a detailed study through a proper quest of the transient impact on the degradation of insulation properties is expected through this work, where it has not given adequate attention in the available literature.

Capacitor banks and variable frequency drives (VFDs) are two widespread applications that come into prominence in the transient study in modern factories. Capacitor banks are deployed for reactive power compensation, while VFDs are intrinsically used by induction motors of different ratings. As the speed of a motor is a function of its sine waves' fundamental frequency, a VFD can control the revolution of the motor to a great extent, since the VFD can alter the fundamental frequency of the waveform, which mimics the sine nature by the count of pulsations in Pulse Width Modulation (PWM). High $d v / d t$, which is produced by IGBTs through its almost perfect square wave, can originate higher transient currents in the leads. They can breed steep fronted voltage pulses [6]. This forms high voltage pulses across the overall inductance of the system. This explains why the cable capacitance and inductance matter more as the switching of pulses increases.

Power loss under alternating field excitation of dielectric material is a well-known phenomenon. However, no clear technical picture is available for energy loss under transient conditions, particularly under ramp or step voltage. This may have given intentional rise as in the case of VFDs or accidentally under switching surges. The comparison of this alternating field excitation and transient excitation has been discussed deeply in previously reported studies [17-20]. Such a study concludes the result that fast transients cause a great energy dissipation in dielectrics [18]. Moreover, such extremely short time steps are very lossy even in relatively fast responding dielectrics.

Even though induction motors are not under serious threat from harmonics as synchronous generators, excessive harmonic stress can drive the equipment to overheat [21-27]. In power systems where capacitors in resonance with the network are enhancing one or few harmonics, this becomes critical with motors. DC converter and regulated AC inverters of VFDs are essentially made with diodes and IGBTs which exhibit nonlinear characteristics. They obviously introduce harmonics to the grid [28]. The increase in iron losses, eddy current, and hysteresis losses further surges the core temperature, since harmonics current has a higher frequency [29-31]. 
Hysteresis loss is a function of frequency, while eddy loss is a function of the square of the frequency. In a supply system with harmonics, there can be multiple higher frequencies. Thus, there will be additional losses for the induction motor [32]. With higher frequencies, the current flow tends to become superficial in the conductor, popularly known as the skin effect. This shrinks the operative area of the conductor leading to an increase of conductor resistance because the resistance is a function of reciprocal of area. Higher copper loss in the motor will then be triggered by this higher resistance.

Most loads of bulk consumers, such as factories, usually record low power factor and lagging, since they are engrained inductive. To improve this and to provide VAR support, a leading mechanism should be adopted in parallel with the load, which can fairly or entirely neutralize the lagging reactive component [1, 27-29]. For this, in general, capacitor banks are heavily used in the industry by applying them to relevant three-phase sections. It also provides the most optimized solution from an economic and engineering standpoint [30]. Switching transient disturbances generated by capacitor banks in the system have been explained in considerable detail by numerous investigators [7, 28, 29, 31-34].

\section{Materials and Methods}

As reported in [13], PicoScope 3206A, $200 \mathrm{MHz}$ oscilloscope, was used to record voltage waveforms with a sampling rate of $500 \mathrm{Ms} / \mathrm{s}$ using a laptop that also operates on its battery. The common-mode transients generated in electrical machines under test were measured using a $1000 \mathrm{x}$ attenuated P6015A Tektronix High Voltage (HV) Probe. PicoScope 6 (version 6.14.10.4759) and MATLAB R2015a were mainly used for data analysis. Since this study measures the transients generated in the electrical machines in different instances, the HV Probe is connected across the respective live line and the system ground. A $1 \mathrm{~m}$ long 3-core cable which complies with BS 6004 [35] was used to link the electrical distribution panel of the machine under test with the HV Probe as depicted in Figure 1. Both power and data channel connectivity of PicoScope were laid separately as illustrated in Figure 1, which ensures that no electromagnetic coupling is applied to the data collected. Proper standards and manufacture specifications were followed at all places where applicable as in [36-39].

The experimental methods that were reported in $[13,38,39]$ are followed in this study to record transients. Transients were recorded at different electrical machines and the capacitor bank assemblies in tea factories in Sri Lanka as illustrated in Figure 2. As a general practice, at every new measurement attempt, 5 to 10 waveforms were used to determine the trigger threshold based on the abundance of transient peaks at each location.

\section{Results}

Five large-to-medium-scaled tea factories in Sri Lanka were observed during the study in light of recording transient pulses. The main focus was kept on three major stages of tea processing, withering, rolling, and drying. These are the stages that induction machines of higher-rated horsepower (hp) are utilized. This particular effort is more biased towards analyzing the voltage transient impact on insulation degradation and impact on capacitor banks. Table 1 indicates the summary of the 314 transient waveforms captured in 55 different attempts in steeply and high amplitude transient prone situations.

Power system instability can occur either as continuous fluctuations of voltage or voltage collapse described by a progressive and fast continuing drop of voltage due to inrush situations in the line or through the system as a whole $[40,41]$. The observations have brought this to witness; due to these inrush situations, both the turning on and off functions of motors generate high amplitude transient pulses bundled with steeply repetitive transients which appear as a burst as depicted in Figure 3.

Figure 4 represents the localized expansion inside the burst in such two inrush voltage transients, which enunciate the steep nature of the repetitive transients.

The quantitative and qualitative form of machine load, the inertia of rotor and load, the ratio of uniform impedance loading, and dynamics in the generation side are the principal factors that affect the severity of voltage instability as previously reported. Uniform impedance loads do not cause transient instability, whereas voltage instability in the form of damped oscillatory way tailed by fast exponential collapse happens after commutation [41]. These observations were proved, since the same was reflected in the analysis of this study as given in Figure 5.

Insulation deterioration and breakdown can occur even at moderate voltage transients due to fatigue created by continuous voltage stress over the service time of the cables. Due to electric field distortion at turns and twists, insulators, especially in motor windings, are predominantly vulnerable to failure. Voltage transients can cause accelerated ageing of insulation without causing instantly visible failure [4], which is slow in coming but will lead to catastrophic failure eventually. Moreover, they can initiate partial discharge activity at local defects in the insulation due to their rate of rising, which is another risk for which electrical engineers must stay on alert. Table 2 reveals the steepness of transients in this regard over the three tea processing stages focused.

As early mentioned, the qualitative form of motor load, which is the interest of inertia of rotor and load, is one of the principal factors that affect the severity of voltage transients. Therefore, the nature of transients produced under heavily and lightly loading conditions of withering and rolling motors are presented in Figure 6. This reveals that the withering section tends to generate high peaks and amplitudes when heavily loaded. However, once they are lightly loaded, it turns to a burst of wider span instead of high amplitude transients. In the rolling section, the situation remains rather the same irrespective of loading condition.

The amplitude of transients is undoubtedly a matter of concern in terms of the impact of transients on voltage stresses imposed on insulation dielectrics. Transient amplitudes in the main two stages, withering and rolling, are compared in Figure 7. Motors used in the withering section 


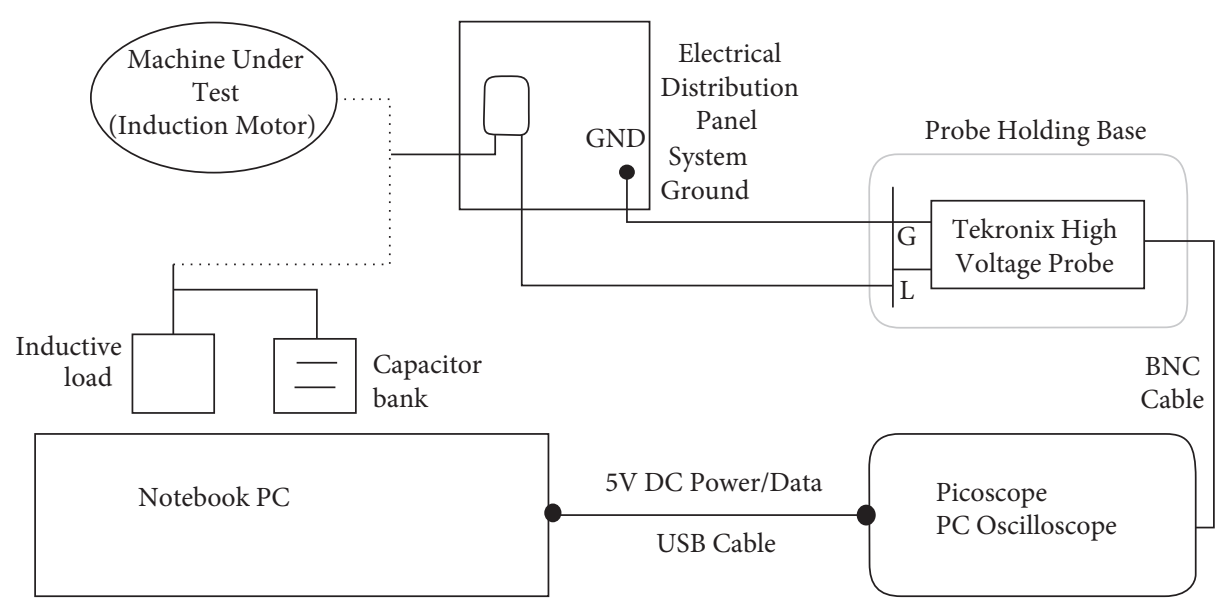

Figure 1: Measurement setup used to record transients in electrical machines.

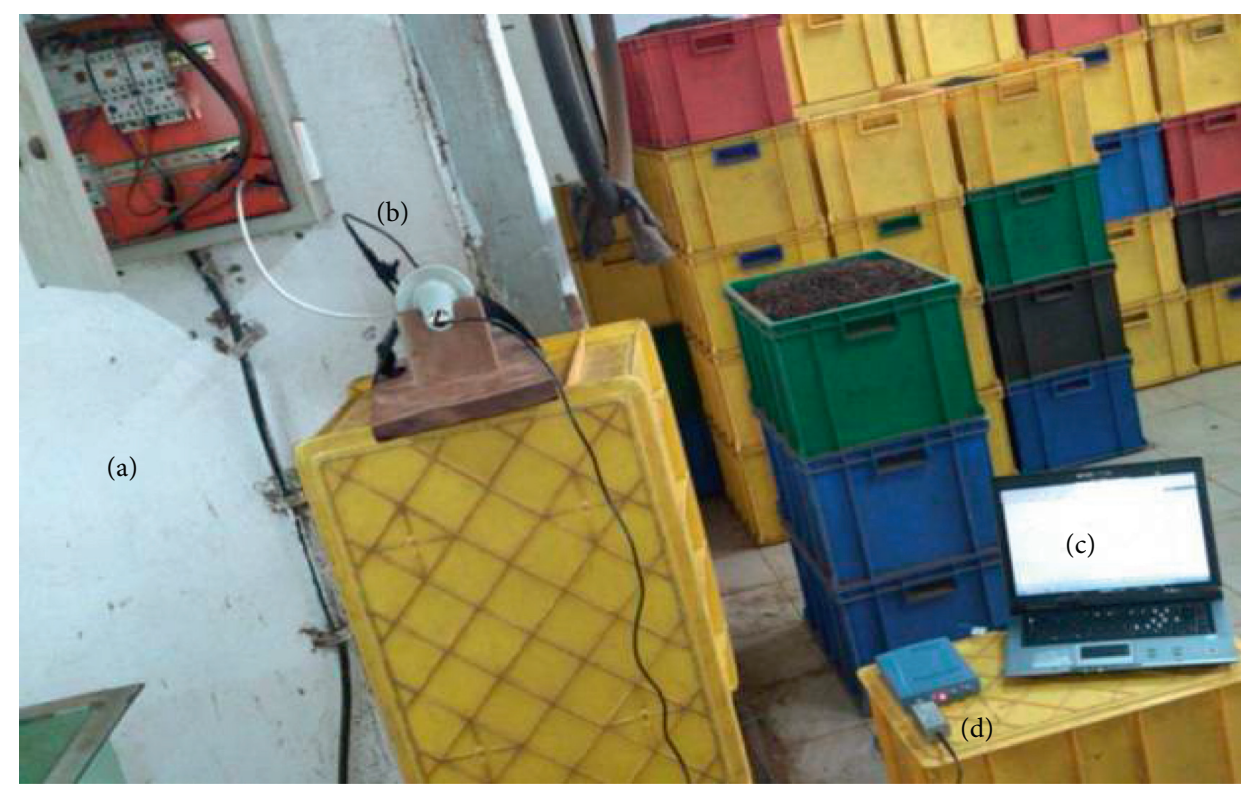

FIgURe 2: Test setup probing a circuit breaker panel at a site. (a) Distribution panel. (b) Tektronix High Voltage Probe. (c) DC powered laptop PC. (d) PICO PC oscilloscope.

TABLE 1: Observation attempts and captured transients.

\begin{tabular}{llccc}
\hline Tea processing machine stage & State of loading & No. of factories visited & Recordings attempts & No. of samples \\
\hline \multirow{2}{*}{ Withering } & Heavily loaded & 5 & 24 & 120 \\
& Lightly loaded & 3 & 8 & 11 \\
\multirow{2}{*}{ Rolling } & Heavily loaded & 5 & 7 & 54 \\
& Lightly loaded & 3 & 5 & 22 \\
\hline Drying & Heavily loaded & 3 & $\mathbf{5 5}$ & 38 \\
\hline Total observations & & & $\mathbf{3 1 4}$ \\
\hline
\end{tabular}

reported the highest peaks in both polarities. Observations in the rolling section establish middle range transient peaks either heavily or lightly loaded. However, they show momentous dominance in amplitude when lightly loaded. This situation is anticipated, since rolling motors are generally held vertical, pressing and rolling the withered leaves downwards, and there is no significant extra torque needed by the motor under either condition, heavily or lightly loaded. Therefore, when motors come to lightly loaded operation after working heavily loaded hours, they are prone to generate higher transient amplitudes.

Insulation breakdown or degradation may occur when the voltage withstand capability is being surpassed by the transients. The insulation breakdown potential depends on 


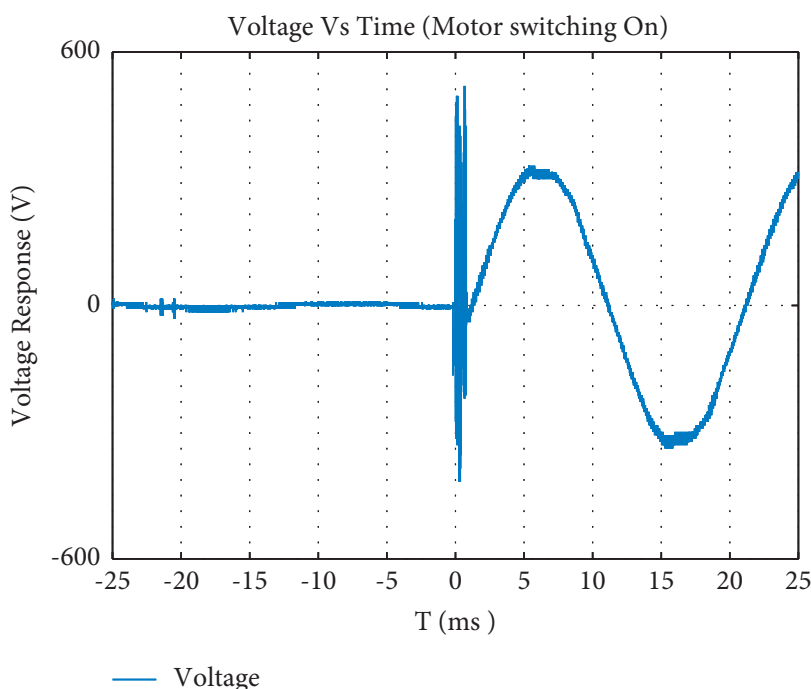

(a)

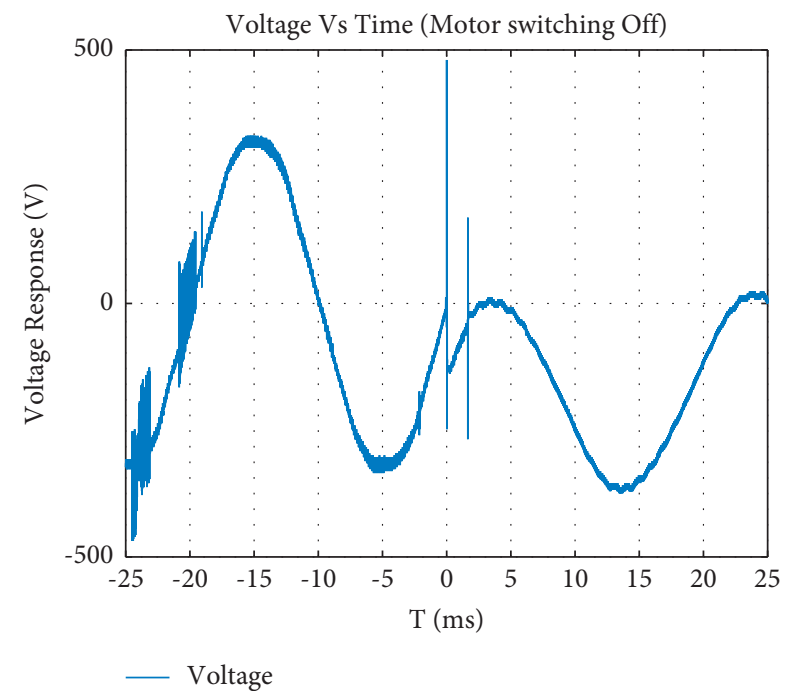

(b)

FIGURE 3: Inrush transient bursts associated with repetitive steep fronted transients recorded from the main contactor of a motor when (a) motor switches on and (b) motor switches off.

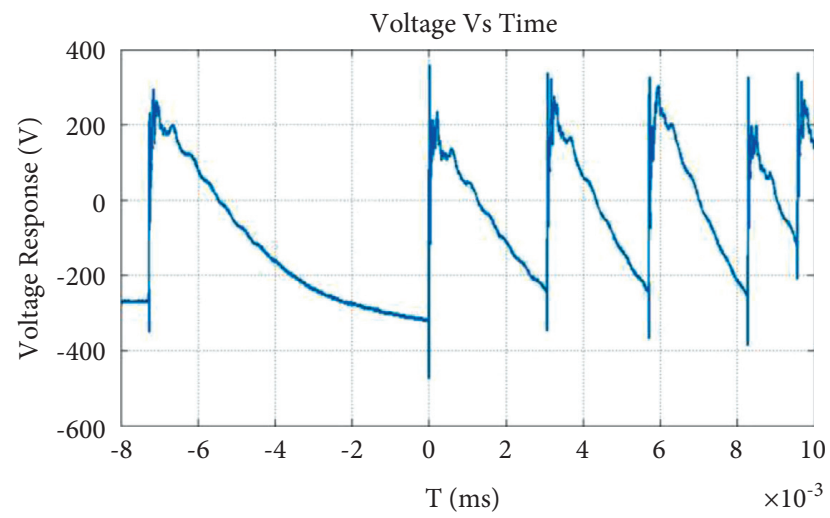

(a)

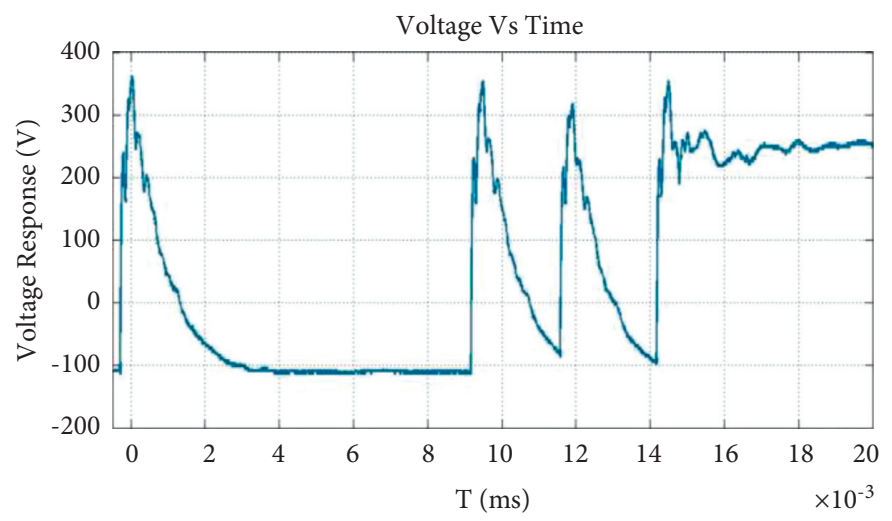

(b)

FIGURE 4: Steep repetitive impulsive transients constituted in a starting inrush transient burst. (a) Direct starter. (b) Star-Delta starter.

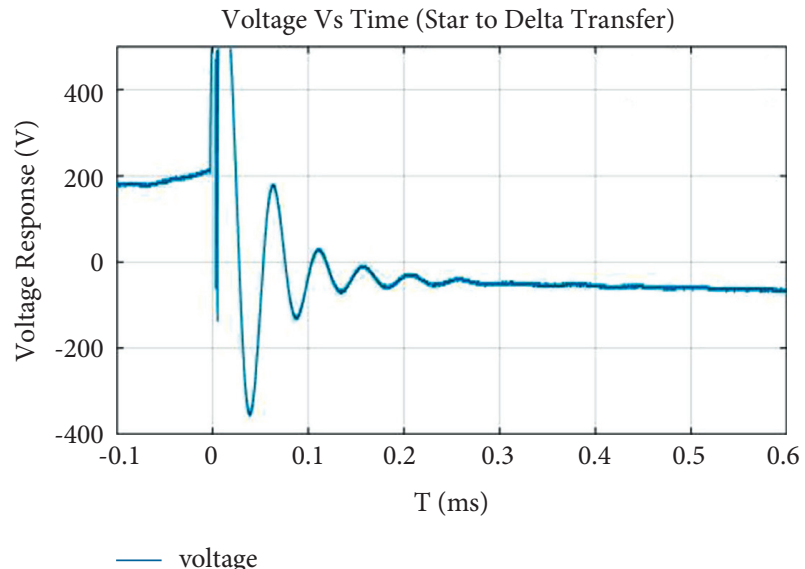

(a)

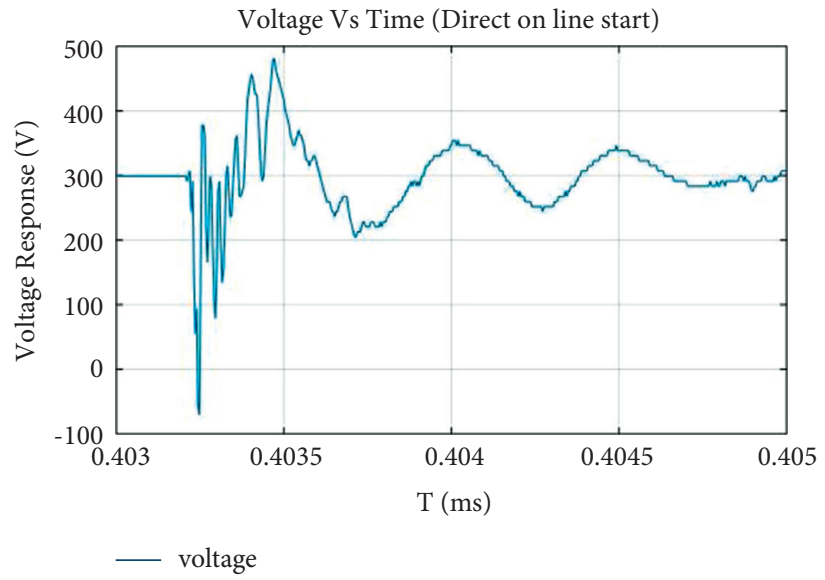

(b)

Figure 5: Transient voltages in the form of impulsive inductive kicks with the steep front which follows oscillatory damps. (a) For a motor with Star-Delta starter, transient spears out at conversion. (b) For a motor with direct online starter. 
TABle 2: The steepness of transients (V/ns).

\begin{tabular}{|c|c|c|c|c|}
\hline \multirow{2}{*}{\multicolumn{2}{|c|}{ Tea processing stage }} & \multicolumn{3}{|c|}{ The steepness of voltage transient $(\nabla V / \nabla t)$} \\
\hline & & \multirow{2}{*}{$\frac{\text { Voltage gap }(\mathrm{V})}{665.2}$} & \multirow{2}{*}{$\frac{\text { Duration }(\mathrm{ns})}{220}$} & \multirow{2}{*}{$\frac{\text { Steepness }(\mathrm{V} / \mu \mathrm{s})}{3023.6}$} \\
\hline & $\operatorname{Max}$ & & & \\
\hline Withering & Average & 494.8 & - & - \\
\hline \multirow{2}{*}{ Rolling } & Max & 464.7 & 160 & 2904.4 \\
\hline & Average & 303.0 & - & - \\
\hline \multirow{2}{*}{ Drying } & Max & 345.6 & 250 & 1382.4 \\
\hline & Average & 137.7 & - & - \\
\hline
\end{tabular}

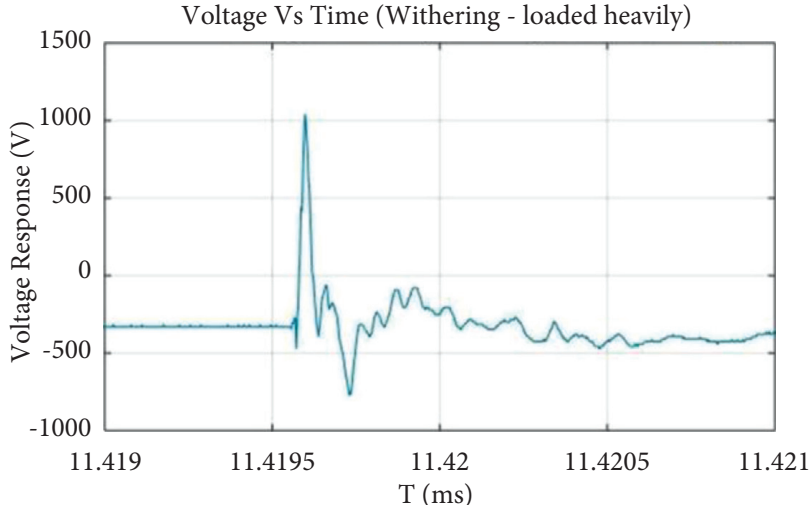

(a)

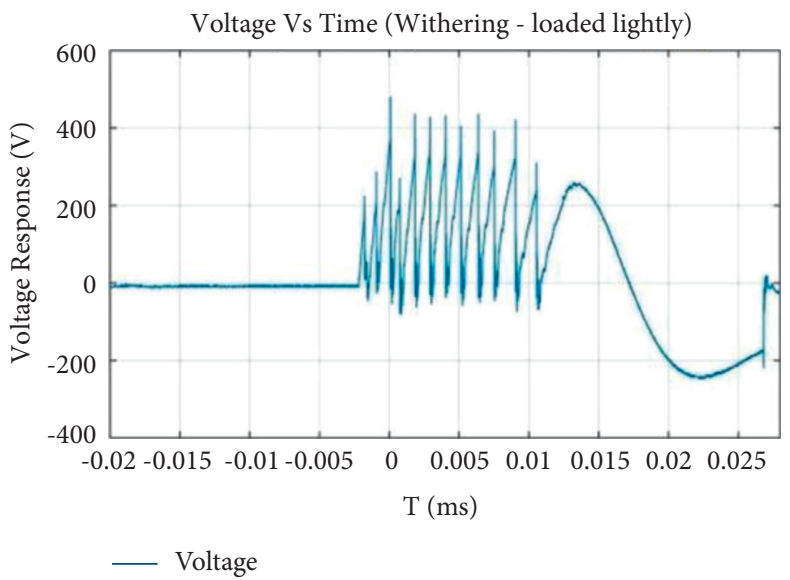

(c)

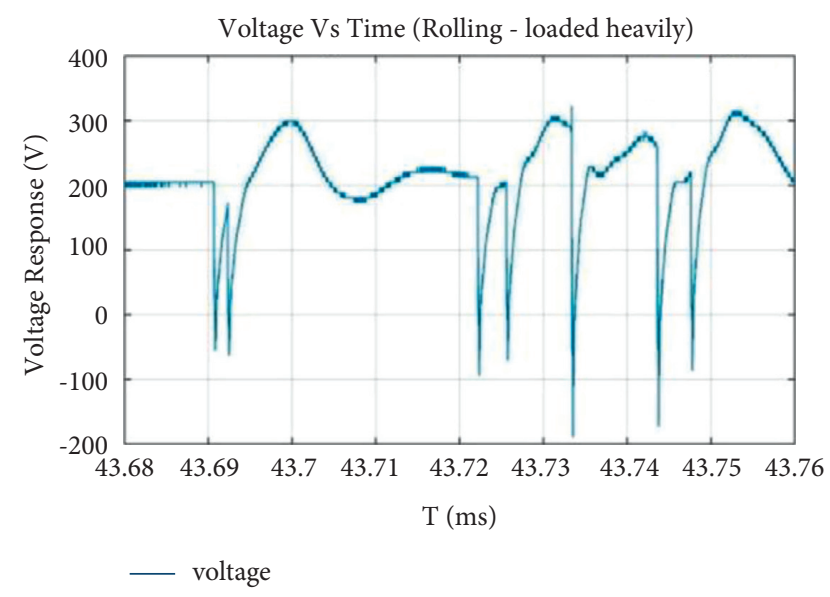

(b)

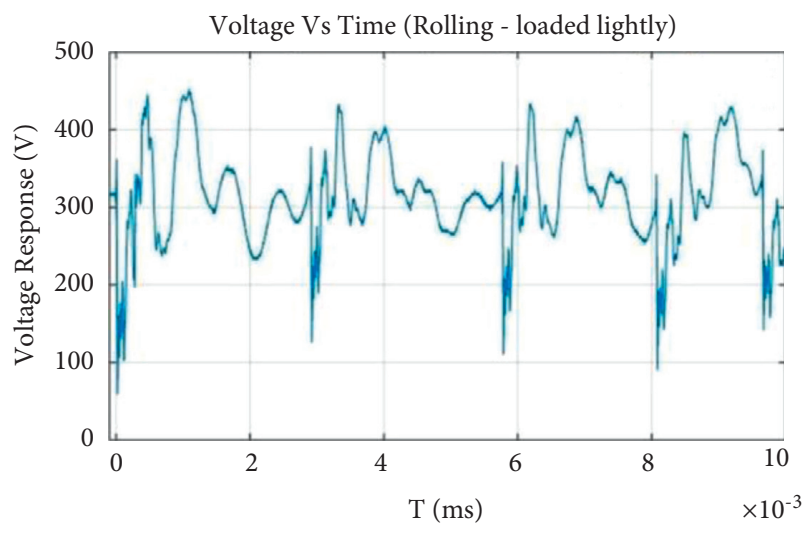

(d)

FIGURE 6: Steep fronted impulsive transients zoomed out from $50 \mathrm{~ms}$ recording windows, $500 \mathrm{MS} / \mathrm{s}$, and sample interval of $2 \mathrm{~ns}$, at two major tea processing stages where heavy induction motors are at service. (a) Withering motor under heavily loaded condition. (b) Rolling motor under heavily loaded condition. (c) Withering motor under lightly loaded condition. (d) Rolling motor under lightly loaded condition.

its voltage-time characteristic. The transient rise time decreases as the breakdown voltage increases. Hence, the rise time of the transient is also an important parameter to review the transient immunity of insulation. Due to the fact that most occurrences of transients appeared as bursts due to the sudden change in circuit conditions, the burst durations are also presented in contrast to the rise times in Figure 8.

In most modelling and simulation carried out to study the transient overvoltages of heavy electrical machines, ideal and fair environments are always assumed [42]. Machines driving at numerous operations were considered in these. The ideal cylindrical rotor machines with mistreated eddy loops, neglected skin or temperature effects, uniform air gap assumption, and identical stator windings are a few of such. However, this analysis has been done based on real on-site observations. Therefore, it uncovers the true transient nature at industrial grounds.

The overvoltage transients with high frequencies, which have been revealed in this study, will make completely disgruntled power infrastructure in any specific electrical 


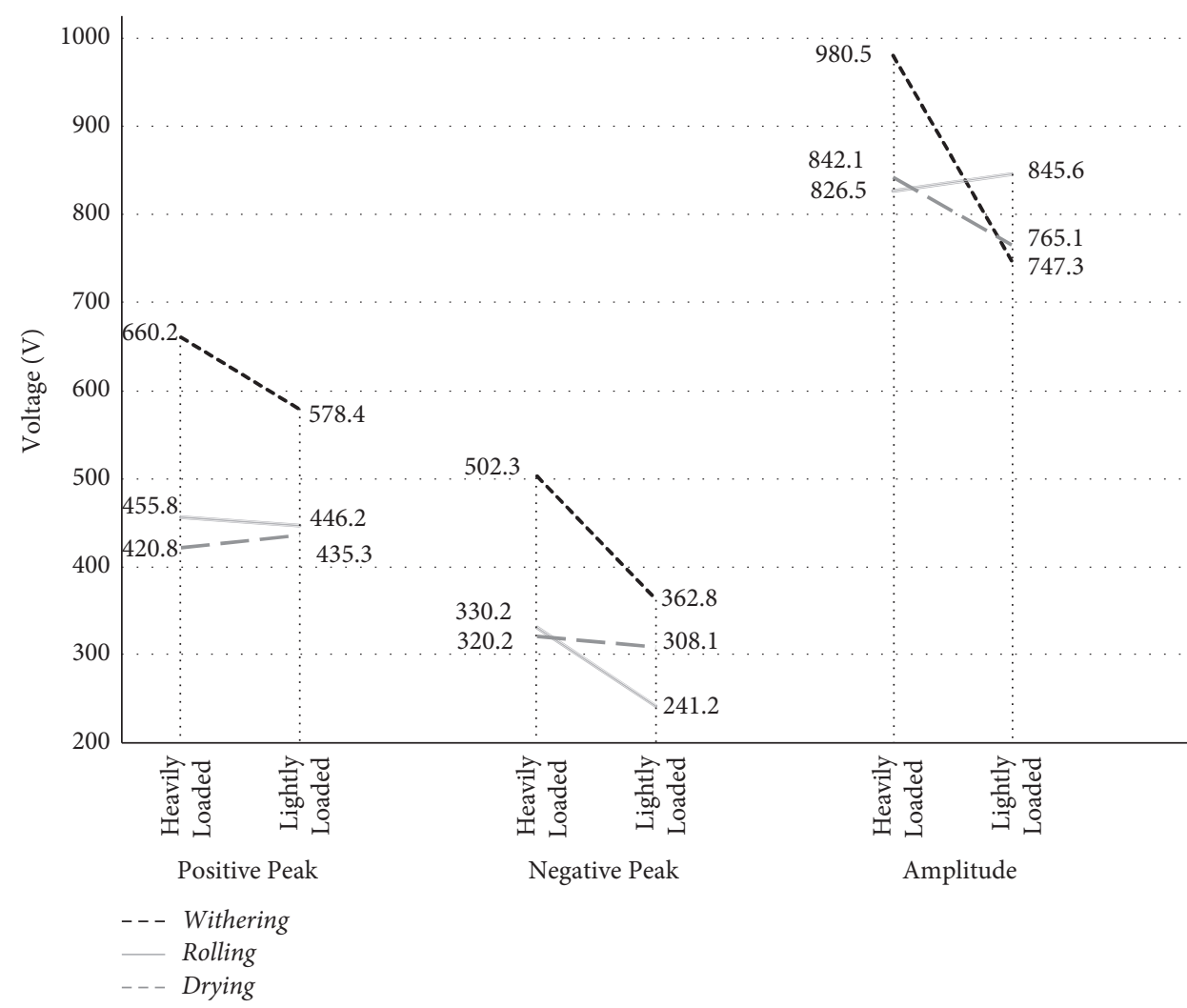

FIgURE 7: Transient amplitudes under heavy and light loading conditions for major processing stages, withering, rolling, and drying.

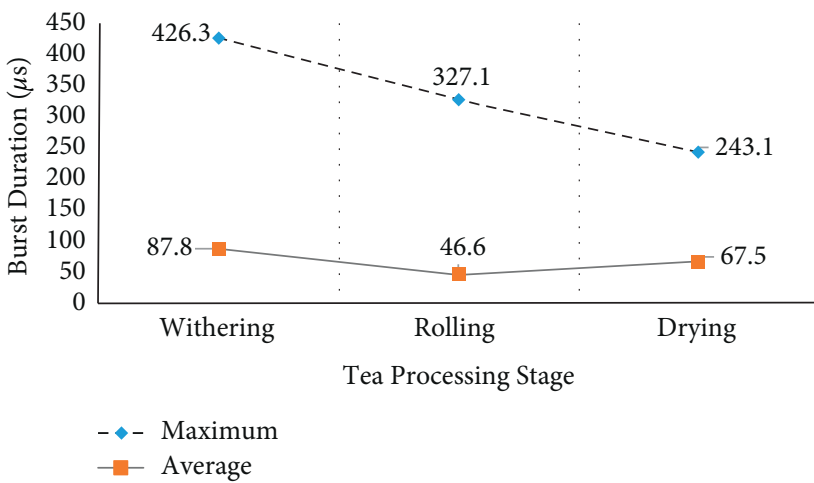

(a)

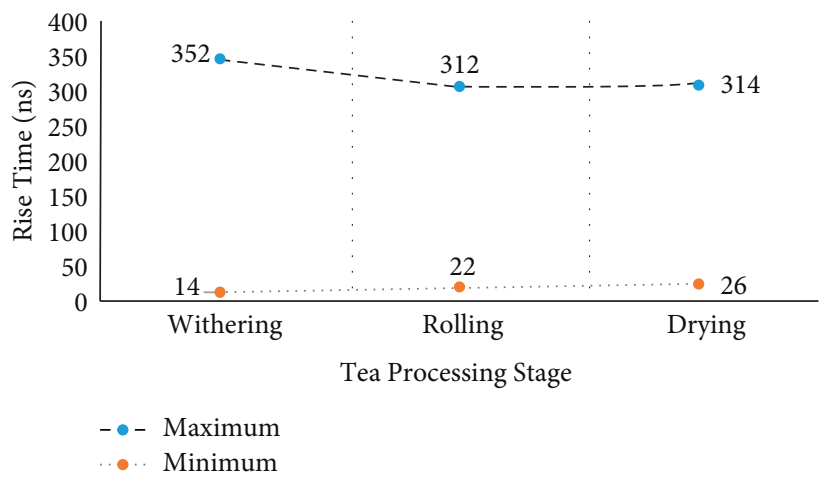

(b)

FIGURE 8: Transient parameters in maximum and average (a) burst durations and (b) rise times.

environment. Skin effect, in which theoretical elaborations were highlighted in the Introduction, is one such. The following rise of conductor resistance and higher copper loss in the motor will then lead to higher mechanical vibrations thereafter, which is beyond the aspirations of this research.

\section{Discussion}

The ameliorative efficiency expectations in the industry have made a great demand to maximize the copper size and minimize the insulation level for the same. This situation has made a space to sensitively design a consistent insulation procedure that essentially calls for broad knowledge of voltage stresses that influence the degradation and deterioration of any insulation system. As it is recognized that the power system transients can stress the insulation of power cables $[4,8]$, the protection level of the power system may necessarily be less than the basic insulation level of the distribution network as a fundamental requirement.

Avoiding transient circulation through a circuit, suppression techniques can be arranged in series with the load to either dampen the energy of a transient or attenuate. They can also be arranged shunt to the load to return the transient back, before flowing across sensitive elements, to ground 
generally, by clamping the voltage or limiting it. Surge protective devices (SPDs) and shielding practices can be used to treat the invasive impact of impulsive voltage transients to the electrical machines like the impact of steeply instantaneous rises. Further, their electromagnetic effect can be controlled to some extent on distribution networks using shielding conductors. The use of preinsertion resistors and inductors in the switching element, the use of synchronous-closing switches with regulators, and applying harmonic filters of suitable rating can overcome the influence of oscillatory transients.

Switching transients have been noticed to make a progressive impact on the insulation of electrical machines. The technical solutions as discussed in [12] like the use of high speed interrupting strategies, novel and high precision techniques for the elimination of arc plasma-like improved arc chutes, using vacuum or SF6 as an insulating medium, high-end design and manufacturing practices have already been taken to mitigate the transient impact to a certain level.

Metal Oxide Varistor (MOV) surge arresters with high energy capacity can be effectively used with motors in the high amplitude domain. However, they are incapable of handling steeply switching voltage surges where a properly rated capacitor is required to be employed to reduce the steepness of transient pulses. A popular theoretical solution to mitigate eddy current losses and skin effects by replacing the solid conductors with stranded cables is also a productive solution here.

As revealed in [41], as the short circuit level between the generating side and load increases, it conserves and regulates the stability of the voltage, while lower short circuit levels put the system at the risk of transient voltage instability. Lower series impedance $(Z)$ can be maintained to improve the situation in such cases. This environment will bring a healthy situation where copper in the insulation is kept less harmed through its operation span, by conserving the insulation also less attacked by numerous effects as discussed early.

The addition of more parallel loads of uniform impedance or reducing their mechanical load hinders the occurrence of transient overvoltages in situations like this study where induction motor machine loads are majorly present. The protection of the motors with MOV is not always the solution like in the case of Vacuum Circuit Breaker applied place. In such environments, C-R surge suppressors can be used to safeguard the motor from repetitive reignition [43]. AC reactors are fitted before the VFD. Reactors may also offer the capability to a certain level to withstand voltage transients created by switching of power factor correction capacitor banks. Consequently, the transient parameters triggered in this study can be effectively used to assess this reactor endurance against manufacturer ratings.

A mounting recognition of transient impacts on power systems, in a high-frequency context, in particular, has awakened in industrial power quality phenomena in the recent past. Due to some critical reasons explained in [44], the limited interest in high-frequency transients in industrial low and medium voltage power systems keeps the danger buried and harasses the electrical machines further.
The spaces occurring in the swollen cables' insulation are the ultimate impact yielded due to high amplitude transients, resulting from corona discharges. Catalyzing with the oxidization process of insulation or physical damage, once electrified, they begin to conduct and develop greater. These imperfections will grow across fracture lines along the direction of the electric field giving water treeing defects. Therefore, voltage transients can initiate partial discharge activity at these local defects on account of peak voltage, high $\mathrm{dv} / \mathrm{dt}$, and high frequency $[4,45,46]$, which leads to early insulation deterioration. At the same time, mechanical abnormalities in motor operation may arise due to these cumulative transient effects [47].

Capacitor banks are extensively used as leading and voltage regulation mechanisms, while capacitors are also used majorly to filter our high-frequency harmonics. On the other hand, switching devices may see lines and cables as capacitive loads. These aggravated capacitive switching demands exceptional care, since the total voltage across the contacts can reach higher values after the interruption. Dielectric breakdown of the switching device might be the consequence.

The frequency-domain analysis reveals more evidence of how insulation will degrade its quality due to high-frequency transient components. The noise that can grow due to stray capacitive and inductive couplings between the system ground and the live line is also assessed here. Nearby delicate solid-state equipment of sensitive applications can go upset due to the impact of electromagnetic coupling [48] of these noises caused by high-frequency components. Figure 9(a) illustrates the transient impulse that appeared in a supply sine wave of a $50 \mathrm{~ms}$ window. Its enlarged burst is shown in Figure 9(b), and frequency plot is shown in Figure 9(c). Even though the two resolutions almost superpose in this plot of Figure 9(c), some transients appeared spread making complex noises in the observations like in the case of Figure 10. When the implications of these frequency-domain analyses are taken to a succinct conclusion, it clearly provides evidence of how the high-frequency components aggravate the risk against insulation quality and succumb it gradually.

To emphasize the relationship between the ageing and failure of insulation in normal sine and transient overvoltage conditions, investigative studies have been carried out [49]. Sine waves in the range of several kilovolts and transient impulse voltages of different characteristics are carried out in them. As explained in [10], the high-frequency impedance has a direct link with the demagnetization of permanent magnet synchronous motors. Tests of lightning impulse conferring the norms using a standardized $1.2 / 50 \mu \mathrm{s}$ waveform failure tests through using a large $\mathrm{d} v / \mathrm{d} t$ impulse voltage like $250 / 2500 \mu$ s transient are popularly done $[49,50]$.

The feeding transients to the grid from the capacitor bank switching can be avoided, setting up smoother engagement. In this, an electronic control can be designed to measure power factor and overvoltage levels which integrates a regulation mechanism that enables smooth stepwise engagement of capacitor bank at advanced step ratio, as 


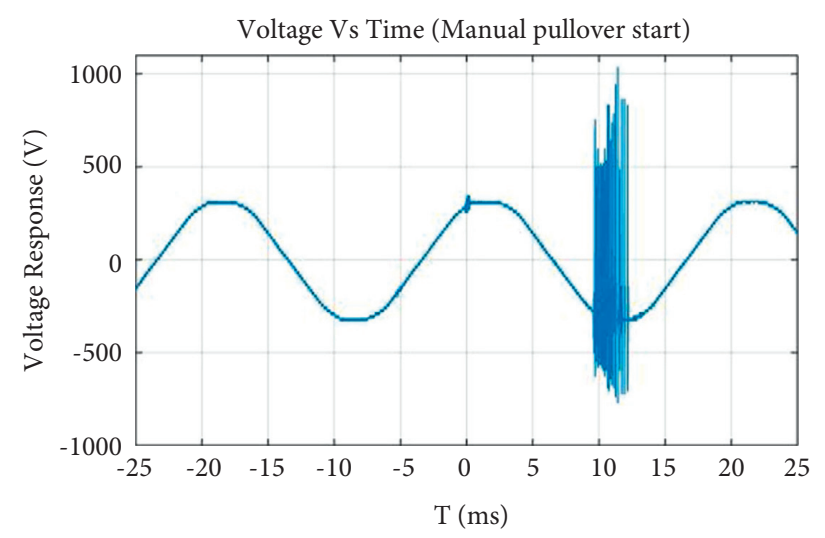

(a)

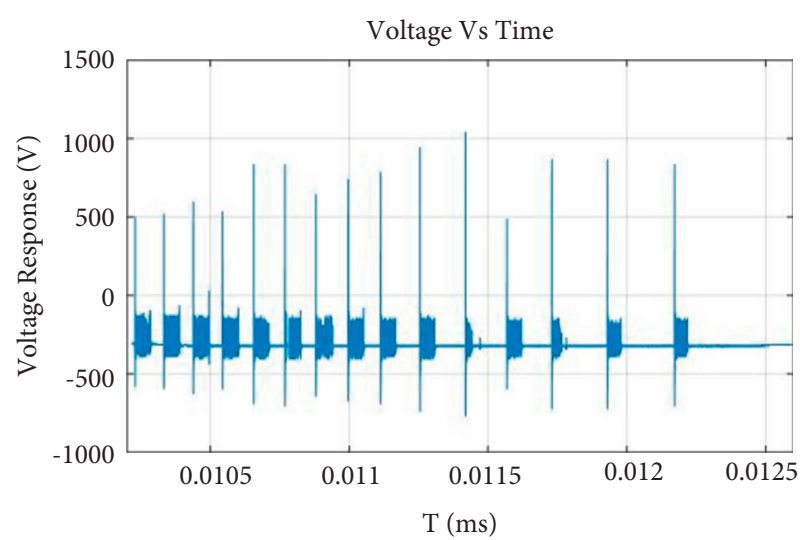

(b)

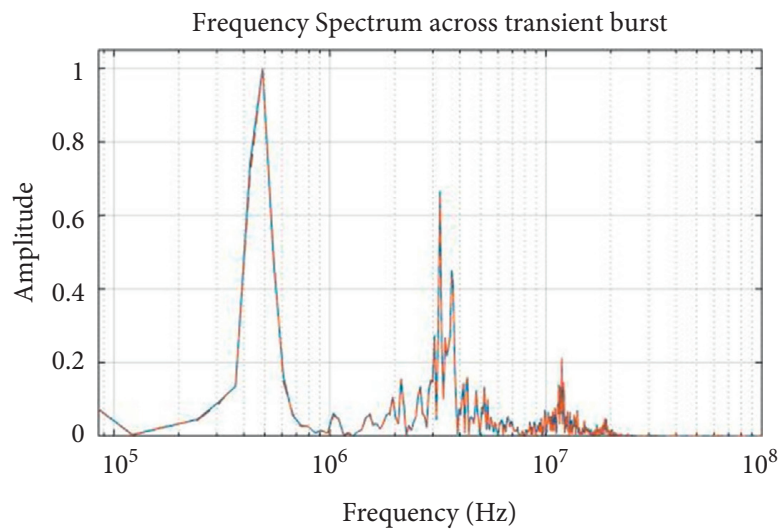

(c)

FiguRE 9: Transient burst appearing in manual direct online pullover start. (a) In 50 ms measurement window. (b) Zoomed out transient impulse in the sine wave. (c) Frequency plot of the impulse.

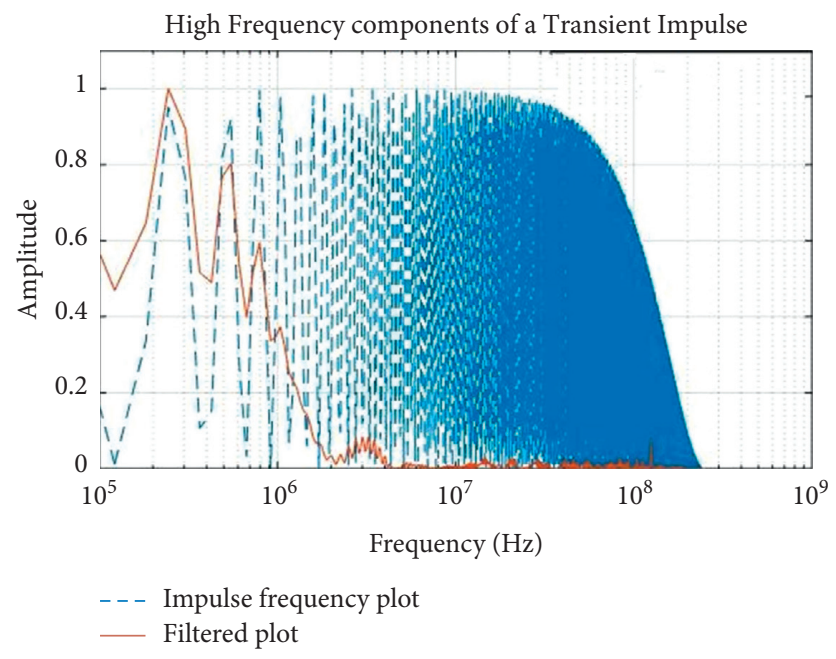

FIgURE 10: Noisy transient impulse with steep rises at different frequencies.

given in Figure 11. Power factor measuring electronic control component was designed in this and given to the respective technical experts of factories as feedback.

Electrical machines employed in the factories investigated, including motors, their respective Star-Delta converters, furnaces, and colour sorters, all were from renowned manufacturers around the globe in which all these manufactures make their products comply with the respective international standards set by authorities like IEC, ANSI, and BS. This vacates any technical mistrust of the manufacturing quality of the instruments in the first place, in which transient signatures can be possibly linked to equipment quality. 


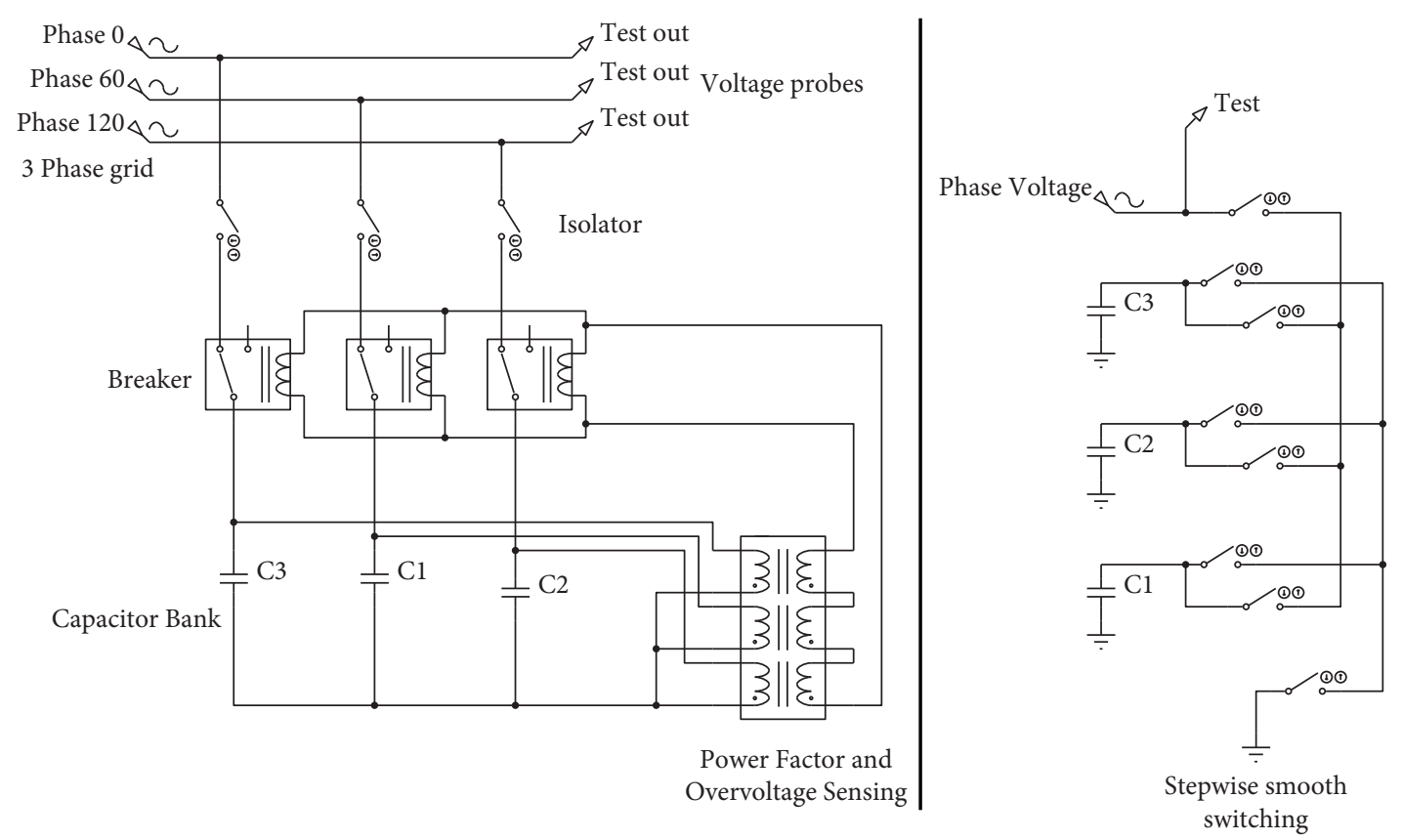

FIGURE 11: Stepwise smooth integration of capacitor banks with power factor monitor circuit.

\section{Conclusions}

During this study, 314 transient waveforms of the $50 \mathrm{~ms}$ measuring window taken in 55 different measuring attempts were taken for analysis. The observation records voltage transients in the form of damped oscillatory way tailed by fast exponential collapse more popularly, which correlates to insulation breakdown having very steep rise as $30.04 \mathrm{~V} / \mathrm{ns}$, which is highest recorded from the withering section. Heavily loaded conditions tend to generate high peak and high amplitude transients, where $688.2 \mathrm{~V}$ is the highest peak value and $980.5 \mathrm{~V}$ is the highest amplitude. There were transient bursts that spread as wide as $426.3 \mu$ s span, while as small as $14 \mathrm{~ns}$ rise time was recorded from withering motors.

Unbalanced transient fluxes and currents are made whenever a decidedly inductive circuit is integrated into an AC voltage system. Three-phase induction machines have invaded industrial floors in the modern era keeping the biggest burden of transient instability. Their straightforward design, reliable and easy operation with handy maintenance demand, small primary cost, great efficiency, and requirement of less technical control gear for starting and rpm control are key reasons in this regard. It is discussed in the literature $[4,6,9,17]$ that the life of insulation becomes shorter when transient amplitude and their repetition rate become higher. Undoubtedly, the insulation failure is correlative to how severe the transient voltage is or the amount of repetitive surge distribution in the network. These were extensively detailed with observations and analysis in the discussion.

Although the fruits of the effort of all past researchers have made their way into introducing protection techniques at different times, the transient effect on system power quality is still to be pictured clearly. Therefore, the voids in the understanding still demand a better characterization of the transient nature in electrical machines, which is decisive to keep the electric power system hassle-free and make troubleshooting convenient. With the said test setup, at five different local tea factories, it was able to strain out transient behaviours and factors of the unbalanced three-phase waveforms. Outcomes of this study can be used to design and assess transient mitigation methods, updating transient test waveforms, susceptibility evaluations, maintenance guidelines, and workforce awareness in the engineering and technology sector.

The transients generated are increasing the supply frequency instantaneously as reported. Hence, it generates electrical resonance across the power supply and capacitor division. These events are responsible for the magnification of the existing current and voltage harmonics. Since both inductive and capacitive reactance depend on frequency, the network inductance and capacitor bank make parallel resonance, where harmonics have a greater chance of getting amplified at these overlap frequencies. Capacitor reactance $\left(X_{L}\right)$ is proportional to the reciprocal of the supply frequency, and when the frequency increases, its competency to avoid harmonics falls significantly. Consequently, the current across capacitor banks will be improved giving joule temperature rise $\left(I^{2} R\right)$ which shortens the capacitor life in the long run. As highlighted from the frequency-based observations through analysis, the possible resonance conditions can generate unnecessary vibrations where the expended energy might cause substantial loss of power and speed drops. The resulting noise levels will add more disturbances that can aggravate electrical hassles to the insulation more. Perhaps, it may be leading to sudden failure in extreme events which needs to be addressed in a dedicated broad study.

\section{Data Availability}

The data used to support the findings of this study are available from the corresponding author upon request. 
Please contact Earl Pannila (chanakyap@sltc.ac.lk) for requests on research data.

\section{Conflicts of Interest}

The authors declare that there are no conflicts of interest regarding the publication of this paper.

\section{Acknowledgments}

The facilities provided by the Department of Physics, University of Colombo, and Faculty of Engineering and Technology, Sri Lanka Technological Campus, are highly acknowledged. The authors wish to thank Sri Lanka Technological Campus, Sri Lanka for providing funds for article processing charge (APC).

\section{References}

[1] R. C. Dugan, M. F. McGranaghan, S. Santoso, and H. Wayne, Electrical Power Systems Quality, pp. 111-166, McGraw-Hill, New York, NY, USA, 2nd edition, 2002.

[2] D. H. G. A. Jayasinghe, K. R. S. Lankapriya, R. Valluvan, and V. Cynthujah, "Scenario analysis of future load profile of Sri Lanka considering demand side management initiatives," in Proceedings of the IEEE Innovative Smart Grid TechnologiesAsia (ISGT Asia), Singapore, 2018.

[3] Public Utilities Commission of Sri Lanka, Study Report on Electricity Demand Curve and System Peak Reduction, Public Utilities Commission of Sri Lanka, Colombo, Sri Lanka, 2012.

[4] R. Nikjoo, N. Taylor, and H. Edin, "Effect of high voltage impulses on surface discharge characteristics of polyethylene," in Proceedings of the 24th Nordic Insulation Symposium on Materials, Components and Diagnostics, pp. 93-97, Copenhagen, Denmark, September 2015.

[5] F. Chiang, "Effects of high frequency voltage stress on air insulation and solid insulation," in Proceedings of the 2010 IEEE Symposium on Product Compliance Engineering, pp. 1-10, Boston, MA, USA, 2010.

[6] C. Petrarca, A. Maffucci, V. Tucci, and M. Vitelli, "Analysis of the voltage distribution in a motor stator winding subjected to steep-fronted surge voltages by means of a multiconductor lossy transmission line model," IEEE Transactions on Energy Conversion, vol. 19, no. 1, pp. 7-17, 2004.

[7] Y. Shirasaka, H. Murase, S. Okabe, and H. Okubo, "Crosssectional comparison of insulation degradation mechanisms and lifetime evaluation of power transmission equipment," IEEE Transactions on Dielectrics and Electrical Insulation, vol. 16, no. 2, pp. 560-573, 2009.

[8] P. J. Tavner, "Review of condition monitoring of rotating electrical machines," IET Electric Power Applications, vol. 2, no. 4, pp. 215-247, 2008.

[9] M. D. Sajid, B. P. Singh, and M. Suryakalavathi, "Experimental and theoretical investigation of transient voltage distribution in an $11 \mathrm{kV}$ industrial motor winding," Energy Procedia, vol. 117, pp. 321-328, 2017.

[10] T. Ishikawa, N. Igarashi, and N. Kurita, "Failure diagnosis for demagnetization in interior permanent magnet synchronous motors," International Journal of Rotating Machinery, vol. 2017, Article ID 2716814, 13 pages, 2017.

[11] T. G. Arora, M. V. Aware, and D. R. Tutakne, "Effect of pulse width modulated voltage on induction motor insulation," in
Proceedings of the 2012 7th IEEE Conference on Industrial Electronics and Applications (ICIEA), Singapore, July 2012.

[12] K. K. Puranik, "Improvement in insulation system of high voltage motors to withstand switching transients," International Journal of Computer Engineering and Applications, vol. 12, 2018.

[13] E. Pannila and M. Edirisinghe, "Transients in low voltage power systems (LVPS) in Sri Lanka under modern domestic environment," in Proceedings of the IEEE 7th International Conference on Information and Automation for Sustainability, Colombo, Sri Lanka, December 2014.

[14] K. Tshiloz, A. C. Smith, A. Mohammed, S. Djurovic, and T. Feehally, "Real-time insulation lifetime monitoring for motor windings," in Proceedings of the 2016 XXII International Conference on Electrical Machines (ICEM), Lausanne, Switzerland, 2016.

[15] J. G. Kim and E. W. Lee, "Analysis of the steep-fronted surge stress in induction motor winding using EMTP," Advanced Computational and Design Techniques in Applied Electromagnetic Systems, vol. 6, pp. 529-532, 1995.

[16] N. Lahoud, J. Faucher, D. Malec, and P. Maussion, "Electrical aging of the insulation of low-voltage machines: model definition and test with the design of experiments," IEEE Transactions on Industrial Electronics, vol. 60, no. 9, pp. 4147-4155, 2013.

[17] G. C. Stone, R. G. van Heeswijk, and R. Bartnikas, "Investigation of the effect of repetitive voltage surges on epoxy insulation," IEEE Transactions on Energy Conversion, vol. 7, no. 4, pp. 754-760, 1992.

[18] A. K. Jonscher, "Dielectric loss under transient excitation," Journal of Physics C: Solid State Physics, vol. 11, no. 14, pp. L601-L606, 1978.

[19] C.-S. Lam, Y. Yang, Q. Zhong, Y. Chen, and K.-W. Lao, "Advanced power electronic converters and power quality conditioning," Journal of Electrical and Computer Engineering, vol. 2018, Article ID 9701013, 2 pages, 2018.

[20] M. K. Arya and S. Wadhwani, "Transient analysis of three phase squirrel cage induction machine using MATLAB," International Journal of Engineering Research in Africa, vol. 1, no. 3, pp. 918-922, 2012.

[21] E. Acha, V. G. Agelidis, O. Anaya-Lara, and T. J. E. Miller, Power Electronic Control in Electrical Systems, pp. 263-289, Elsevier, Amsterdam, Netherlands, 2012.

[22] H. Oraee and S. Filizadeh, "The impact of harmonic orders on insulation aging in electric motors," in Proceedings of the 36th Universities Power Engineering Conference, pp. 21-26, University of Wales, Cardiff, UK, 2001.

[23] A. Subramaniam, A. Sahoo, S. S. Manohar, and S. K. Panda, "Voltage and current-harmonics induced ageing in electrical insulation," in Proceedings of the 2017 International Symposium on Electrical Insulating Materials (ISEIM), pp. 403-406, Toyohashi, Japan, 2017.

[24] A. Trianni, E. Cagno, and D. Accordini, "Energy efficiency measures in electric motors systems: a novel classification highlighting specific implications in their adoption," Applied Energy, vol. 252, Article ID 113481, 2019.

[25] M. H. Shwehdi, "Harmonics effect in industrial and university environments," Power Quality Harmonics Analysis and Real Measurements Data, IntechOpen, London, UK, 2011.

[26] M. T. Riaz, M. M. Afzal, S. M. Aaqib, and H. Ali, “Analysis and evaluating the effect of harmonic distortion levels in industry," in Proceedings of the 2021 4th International Conference on Energy Conservation and Efficiency (ICECE), pp. 1-7, Lahore, Pakistan, 2021. 
[27] V. K. Metha and R. Metha, Principles of Power Systems, pp. 96-120, S. Chand \& Company Ltd, New Delhi, India, 3rd edition, 2005.

[28] S. A. Ali, "Capacitor banks switching transients in power systems," Energy Science and Technology, vol. 2, no. 2, pp. 62-73, 2011.

[29] T. Patcharoen and A. Ngaopitakkul, "Analysis of transient signals in a substation capacitor bank system using an experimental setup," International Review of Economics Education, vol. 11, no. 3, pp. 284-295, 2016.

[30] T. A. Short, "Electric power distribution handbook," Electric Power Research Institute, pp. 284-325, CRC Press LLC, Boca Raton, FL, USA, 2nd edition, 2014.

[31] I. Nisja, M. Zoni, and Arnita, "Study of capacitor bank switching transient in distribution network," MATEC Web of Conferences, vol. 248, Article ID 02004, 2018.

[32] M. M. Saied, "Capacitor switching transients: analysis and proposed technique for identifying capacitor size and location," IEEE Transactions on Power Delivery, vol. 19, no. 2, pp. 759-765, 2004.

[33] M. Taherzadeh, R. Rostaminia, M. Joorabian, and M. Saniei, "Mitigation of capacitor bank switching transients by using SVCs in large plants instead of capacitor bank and circuit breaker," in Proceedings of the 4th Annual International Power Electronics, Drive Systems and Technologies Conference, pp. 321-327, Tehran, Iran, 2013.

[34] T. Lazimov and R. Ahmadov, "Some features of capacitor banks automatic switching-offs computer simulation," IFACPapersOnLine, vol. 51, no. 30, pp. 632-635, 2018.

[35] BS 6004:2012+A1:2020 - Electric cables, PVC insulated and PVC sheathed cables for voltages up to and including 300/500 $V$, for electric power and lighting.

[36] BS 546 - Two-Pole and Earthing-Pin Plugs, Socket-Outlets and Socket-Outlet Adaptors for AC (50-60 Hz) Circuits Up To 250 $V$.

[37] BS 6500 - Electric cables Flexible cords rated up to 300/500 V, for use with appliances and equipment intended for domestic, office and similar environments.

[38] E. Pannila and M. Edirisinghe, "Power system switching transients in passenger automobiles," in Proceedings of the IEEE 7th International Conference on Automation and Sustainability, Colombo, Sri Lanka, December 2014.

[39] E. Pannila and M. Edirisinghe, "Characterization of switching transients in low voltage power systems of tea factories in Sri Lanka," European Journal of Engineering Education, vol. 22, no. 4-5, pp. 325-334, 2020.

[40] Y. A. Mobarak and M. M. Hussein, "Voltage instability and voltage collapse as influenced by cold inrush current," ICGSTACSE Journal, vol. 12, no. 1, 2012.

[41] M. Z. El-Sadek and F. N. Abdelbarr, "Effects of induction motor load in provoking transient voltage instabilities in power systems," Electric Power Systems Research, vol. 17, no. 2, pp. 119-127, 1989.

[42] O. I. Okoro, "Steady state and transient analysis of induction motor driving a pump load," Nigerian Journal of Technology, vol. 22, no. 1, pp. 46-53, 2003.

[43] M. A. Ebrahim, T. Elyan, F. Wadie, and M. A. Abd-Allah, "High frequency spectrum analysis of transient overvoltage across VCB switched large induction motors," International Journal of Applied Science and Engineering Research, vol. 4, no. $5,2015$.

[44] H. De Herdt, J. Declercq, T. Sels, T. Van Craenenbroeck, and D. Van Dommelen, "Fast transients and their effect on transformer insulation: simulation and measurements," in
Proceedings of the 16th International Conference and Exhibition on Electricity Distribution (CIRED 2001), pp. 1-6, Amsterdam, Netherlands, 2001.

[45] Y. Shakweh, Chapter 29-Drive Types and Specifications, Power Electronics Handbook, pp. 913-944, Butterworth-Heinemann, Oxford, UK, 4th edition, 2018.

[46] X. Bi, A. Ren, S. Li, M. Han, Q. Li, and Q. Li, "An advanced partial discharge recognition strategy of power cable," Journal of Electrical and Computer Engineering, vol. 2015, Article ID 174538, 11 pages, 2015.

[47] A. M. Trzynadlowski, "Detection of mechanical abnormalities in induction motors by electric measurements," International Journal of Rotating Machinery, vol. 5, Article ID 475101, 12 pages, 1999.

[48] M. Camp and H. Garbe, "Susceptibility of personal computer systems to fast transient electromagnetic pulses," IEEE Transactions on Electromagnetic Compatibility, vol. 48, no. 4, pp. 829-833, 2006.

[49] R. Liao, C. Lv, L. Yang, Y. Zhang, W. Wu, and C. Tang, "The insulation properties of oil-impregnated insulation paper reinforced with nano- $\mathrm{TiO}_{2}$," Journal of Nanomaterials, vol. 2013, Article ID 373959, 7 pages, 2013.

[50] T. Sels, J. Karas, J. Lopez-Roldan, J. Declercq, D. Van Dommelen, and R. Belmans, "Electrical insulation behaviour subject to fast transients using a tesla transformer," in Proceedings of the 6th International Multi Conference on Power and Energy Systems (IASTED), Marina Del Rey, CA, USA, 2002. 